\title{
Complementary Dynamics of Banana Root Colonization by the Plant Growth-Promoting Rhizobacteria Bacillus amyloliquefaciens Bs006 and Pseudomonas palleroniana Ps006 at Spatial and Temporal Scales
}

\author{
Rocío Margarita Gamez ${ }^{1}$ (D) - Sandra Ramirez ${ }^{2}$ (D) - Martha Montes ${ }^{3}$ (D) - Massimiliano Cardinale M,5 $_{\text {(iD }}$
}

Received: 1 April 2020 / Accepted: 3 August 2020 / Published online: 11 August 2020

(C) The Author(s) 2020

\begin{abstract}
Banana (Musa acuminata) growth for commercial purposes requires high amounts of chemical fertilizers, generating high costs and deleterious effects on the environment. In a previous study, we demonstrated that two plant growthpromoting rhizobacteria (PGPR), Bacillus amyloliquefaciens Bs006 and Pseudomonas palleroniana Ps006, isolated in Colombia, could partially replace chemical fertilizers for banana seedling growth. In a second work, the effects of the two inoculants on banana transcripts were found to occur at different times, earlier for Bs006 and later for Ps006. This leads to the hypothesis that the two rhizobacteria have different colonization dynamics. Accordingly, the aim of this work was to analyze the dynamics of root colonization of the two PGPR, Bs006 and Ps006, on banana growth over a time frame of 30 days. We used fluorescence in situ hybridization (FISH) and confocal laser scanning microscopy (CLSM), followed by three-dimensional reconstruction and quantitative image analysis. Bacillus amyloliquefaciens Bs006 abundantly colonized banana roots earlier (from 1 to $48 \mathrm{~h}$ ), ectophytically on the rhizoplane, and then decreased. Pseudomonas palleroniana Ps006 was initially scarce, but after $96 \mathrm{~h}$ it increased dramatically and became clearly endophytic. Here we identify and discuss the potential genetic factors responsible for this complementary behavior. This information is crucial for optimizing the formulation of an effective biofertilizer for banana and its inoculation strategy.
\end{abstract}

Keywords Banana cv. Williams · Plant growth-promoting rhizobacteria (PGPR) Bacillus $\cdot$ Pseudomonas $\cdot$ Fluorescence in situ hybridization-confocal laser scanning microscopy (FISH-CLSM) · Colonization dynamics

Electronic supplementary material The online version of this article (https://doi.org/10.1007/s00248-020-01571-0) contains supplementary material, which is available to authorized users.

Massimiliano Cardinale

massimiliano.cardinale@unisalento.it

Rocío Margarita Gamez

rgamez@agrosavia.co

Sandra Ramirez

sandrar_587@hotmail.com

Martha Montes

mmontes@agrosavia.co

1 Corporación Colombiana de Investigación Agropecuaria Agrosavia, C.I. Turipaná, Montería, Cordoba, Colombia
2 Corporación Colombiana de Investigación Agropecuaria Agrosavia, C.I. Tibaitatá, Mosquera, Cundinamarca, Colombia

3 Corporación Colombiana de Investigación Agropecuaria Agrosavia, C.I. Caribia, Zona Bananera, Magdalena, Colombia

4 Institute of Applied Microbiology, Justus-Liebig-University Giessen, Giessen, Germany

5 Department of Biological and Environmental Sciences and Technologies - DiSTeBA, University of Salento, Centro Ecotekne via Provinciale Lecce-Monteroni, I-73100 Lecce, Italy 


\section{Introduction}

Approximately 5.6 million hectares of land are dedicated to banana production globally, according to the latest Food and Agriculture Organization Corporate Statistical Database (FAOSTAT) available data from 2017 [1]. Large amounts of fertilizers are required to maintain high yields [2], representing high costs and a potential environmental threat. Biofertilizers are environmentally-friendly alternatives to chemical fertilization for the stimulation of plant growth. They are based on beneficial rhizobacteria, usually designated as plant growthpromoting rhizobacteria (PGPR). These microbial species applied to seeds, seedlings, or leaves can increase seed germination, plant biomass, and crop yield [2-10]. Treatments with PGPR have been used to reduce germination time and increase the growth of various crops including vegetables [11-13] and fruits such as apricot, cherry, raspberry, apple, and banana [14-19].

The plant growth-promoting mechanisms of rhizobacteria are based on either direct interaction with the host plant or indirectly via antagonistic activity against phytopathogens $[20,21]$. Direct mechanisms include the ability to produce plant hormones (auxins [22, 23], cytokinins [24], gibberellins [25], and ethylene [24]), symbiotic and asymbiotic $\mathrm{N}_{2}$ fixation $[8,26]$, inorganic phosphate solubilization, and mineralization of organic phosphates and other nutrients, or both [25, 27]. Indirect mechanisms (antagonism against phytopathogens) can be achieved by siderophore production, synthesis of antibiotics or cell wall-degrading enzymes, competition for binding sites, and the recently discovered root-hair endophyte stacking (RHESt) mechanism [28-31].

Among the effective PGPR, strains of Bacillus and Pseudomonas have been widely studied in various crops, and some commercial biofertilizers are based on species belonging to both genera. For several years, we have been conducting research to identify suitable PGPR to be used as beneficial inoculants on banana cv. Williams, which is of great economic interest for several banana-producing countries, including Colombia. In a previous study [32], we selected the strains Bacillus amyloliquefaciens Bs006 and Pseudomonas palleroniana Ps006 (formerly Pseudomonas fluorescens Ps006) as the best-performing PGPR among a group of potential candidates isolated in Colombia. In another study [33], we investigated the effect of these two strains on banana by plant transcriptomics. We observed that the effects occurred at different moments, being Bs006 stronger at an earlier stage, while Ps006 induced more changes later. B. amyloliquefaciens Bs006 and P. palleroniana Ps006 stimulated differential gene expression involved in plant growth promotion at different times, indicating that they use different metabolic pathways. These observations lead to the hypothesis that the two strains might colonize banana roots with different dynamics and different behaviors at both temporal and spatial scales.

In the current study, we tested this hypothesis as follows. We investigated the dynamics of banana root colonization by these two strains over a time frame of 30 days after inoculation, expecting the following: (i) $B$. amyloliquefaciens $\mathrm{Bs} 006$ and $P$. palleroniana Ps006 colonize banana roots with different dynamics over the considered time scale (Bs006 earlier, Ps006 later), and (ii) both PGPR colonize different microniches of banana roots at a spatial scale. Fluorescence in situ hybridization (FISH) staining [34] coupled with confocal laser scanning microscopy (FISH-CLSM) was used as a detection method, as it enables accurate localization of bacteria in the root habitat, as well as a reliable characterization of the colonization patterns and dynamics [35]. Finally, we performed an in silico genome analysis of the strains Bs006 and Ps006 to compare their genetic background in terms of genes involved in plant growthpromoting activity and plant-microbe interactions, to identify the genetic basis potentially responsible for the different colonization patterns.

\section{Materials and Methods}

\section{Plant Material}

Banana plants (Musa acuminata Colla) of the cultivar "Williams" (Cavendish subgroup, genome AAA) were used in this study. The mother plants were obtained from the ex vitro Musa Bank of the Caribia Research Center of the Corporación Colombiana de Investigación Agropecuaria (AGROSAVIA), formerly known as CORPOICA, Colombia. Murashige and Skoog (MS) culture medium [36], supplemented with $0.1 \mathrm{~g} \mathrm{l}^{-1}$ myo-inositol, $3 \mathrm{ppm}$ (ppm) benzyl amino purine (BAP), $0.5 \mathrm{ppm}$ indole acetic acid (IAA), $1 \mathrm{ppm}$ thiamine hydrochloride, and $30 \mathrm{~g}^{-1}$ sucrose at $\mathrm{pH}$ 5.7, was used for seedling micropropagation in the laboratory by meristem extraction and in vitro propagation/rooting of the seedlings. An in-house AGROSAVIA standardized protocol developed to provide local small farmers with high-quality plants was used. From a healthy banana plant, a basal corm (weight of 300-400 g) was extracted; successive cuts, washes, and disinfection with detergent powder, iodine, and chlorine were carried out until only the apical meristem $\left(\sim 1 \mathrm{~cm}^{2}\right)$ remained for micropropagation (Fig. S1). After leaf emergence (usually after 15 days), the seedlings were transferred to a growth chamber for an additional 4 weeks of growth under the following conditions: $23 / 20{ }^{\circ} \mathrm{C} \pm 1{ }^{\circ} \mathrm{C}$ day/night temperature, 16/8-h light/dark photoperiod, and $65 \% \pm 10 \%$ relative humidity (Fig. S1). 


\section{Bacterial Inoculants}

Two rhizobacteria strains, B. amyloliquefaciens Bs006 and P. palleroniana Ps006, obtained from the AGROSAVIA microbial collection were used. These strains, isolated in Colombia from Physalis peruviana and Furcraea andina, respectively, were already identified at the genome level $[37,38]$ and were selected as the best-performing plant growth promoters on banana in a previous study [32]. They are part of the AGROSAVIA bank of microorganisms. Initially [38], strain Ps006 had been classified as Pseudomonas fluorescens; however, in July 2019 it was reclassified by the NCBI (www.ncbi.nlm.nih.gov/nuccore/ LRMR00000000). The strain Bs006 is currently undergoing a reclassification into the species Bacillus velezensis [39]. Nonetheless, the process is still under consideration, and therefore in this manuscript we kept it as B. amyloliquefaciens.

\section{Planting, Microbial Inoculation, and Sampling}

Seedlings $1-3 \mathrm{~cm}$ in height with three fully developed leaves and adequate root development were selected for transplantation into a new culture medium. After in vitro rooting, the seedlings were inoculated with $5 \mathrm{ml}$ of the microbial inoculants B. amyloliquefaciens Bs006 and P. palleroniana Ps006. Control plants (without microbial amendment) were inoculated with $5 \mathrm{ml}$ of sterile distilled water. Three treatments were evaluated: (1) plants inoculated with B. amyloliquefaciens Bs006, (2) plants inoculated with P. palleroniana Ps006, and (3) control plants without inoculum. For each treatment, three biological replicates, corresponding to plants grown in different containers, were analyzed. Five sampling times were chosen: 1 h, 48 h, 96 h, 15 days, and 30 days, assigned codes T1, T2, T3, T4, and T5, respectively. Samples were fixed for FISH analysis immediately after sampling.

\section{Fluorescence In Situ Hybridization and Confocal Laser Scanning Microscopy (FISH-CLSM) Analysis}

FISH staining was performed following the "in-tube FISH" protocol [40]. The bacterial EUB338MIX universal probe [41] labeled with $\mathrm{Cy} 3$ was used to stain the bacterial cells on inoculated and uninoculated roots. As a FISH negative control, subsamples of inoculated roots were hybridized with a Cy3-labeled NONEUB probe [42].

Stained samples were preliminary checked under a Zeiss Axioplan fluorescence microscope (Zeiss, Jena, Germany), using the Filter Set 15 . They were then extensively observed with the Leica SP8 confocal laser system (Leica Microsystems, Wetzlar, Germany). The $561 \mathrm{~nm}$ laser light was used for the excitation of $\mathrm{Cy} 3$, and emitted light was detected in the range of $565-620 \mathrm{~nm}$; the root tissue was excited with $405 \mathrm{~nm}$ laser light, and the emitted autofluorescence was detected in the range of 428$510 \mathrm{~nm}$. The two signals were combined in multicolored images, where the inoculated bacteria were observed in red and the root tissue in cyan. For each bacterium and time point, three root samples were comprehensively observed. Three representative confocal series were then acquired using the $63 \times$ objective, with a step of $0.45-0.80 \mu \mathrm{m}$ between the confocal planes, and analyzed using Imaris 8.1 software (Bitplane, Zürich, Switzerland). Each confocal series contained between 4 and 65 optical slices (two channel images per optical slice at a resolution of $1024 * 1024 \mathrm{dpi}$ ), for a total of 1602 individual images analyzed. Three-dimensional models were created by converting bacterial signals into spheres and root tissues into isosurfaces. The number of spheres and root volumes were measured automatically by Imaris software and used to calculate the cell density as the number of cells $/ \mathrm{cm}^{3}$ of root tissue. The cell densities of the two strains over the whole time frame were compared by Spearman's rho correlation (the variable did not show a normal distribution), using SPSS version 20 software (IBM Corporation, Armonk, NY, USA). The Adobe Photoshop CS6 program (Adobe Systems Inc., San Jose, CA, USA) was used to assemble and label the final images.

\section{In Silico Analysis of the Genome for Plant Growth- Promoting Activity}

\section{Bacterial DNA Extraction and Amplification}

The SureSelect ${ }^{\mathrm{QXT}}$ Target Enrichment system for the Illumina multiplexed sequencing kit (Agilent Technologies, Santa Clara, CA, USA) was used to obtain the genome sequence. A volume

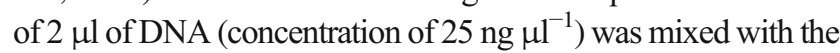
kit buffer and the Herculase enzyme to generate enzymatic fragmentation; the adapters were then added to the ends of the fragments in a single reaction. The DNA libraries were amplified by polymerase chain reacion (PCR) using labeled primers; the amplified libraries were purified with AMPure XP pearls (Beckman Coulter, Brea, CA, USA). Finally, the quantity and quality of the DNA were tested with the Agilent 2100 Bioanalyzer (Agilent Technologies, Inc.), using a high-sensitivity DNA assay. Fragment length ranged between 300 and 2000 bp.

\section{Sanger Sequencing of the Complete Bacterial Genomes}

The PCR product was purified by mixing $5 \mu$ of the amplified product with $2 \mu \mathrm{l}$ of ExoSAP-ITTM PCR Product Cleanup Reagent (Applied Biosystems, Foster City, CA, USA), and incubating at $37^{\circ} \mathrm{C}$ for $60 \mathrm{~min}$ and at $80^{\circ} \mathrm{C}$ for $15 \mathrm{~min}$. Sequencing was performed with the BigDye ${ }^{\mathrm{TM}}$ Terminator v3.1 Cycle Sequencing Kit (Applied Biosystems), by mixing $4 \mu$ of the kit mixture, $2 \mu \mathrm{l}$ of each of the forward or reverse primers $(3.2 \mu \mathrm{M})$ included in the kit, $2 \mu \mathrm{l}$ of the purified PCR product, and $2 \mu \mathrm{l}$ of molecular-grade water. The PCR program began with denaturation at $96{ }^{\circ} \mathrm{C}$ for $1 \mathrm{~min}$, followed by 25 cycles $\left(10 \mathrm{~s}\right.$ at $96^{\circ} \mathrm{C}, 5 \mathrm{~s}$ at $50^{\circ} \mathrm{C}$, and $4 \mathrm{~min}$ at $60^{\circ} \mathrm{C}$ ). The sequencing 
product was purified with the BigDye XTerminator ${ }^{\mathrm{TM}}$ Purification Kit (Applied Biosystems), taking $10 \mu \mathrm{l}$ of the XTerminator solution and mixing with $12 \mu \mathrm{l}$ of the sequencing product and $45 \mu \mathrm{l}$ S-adenosylmethionine (SAM) buffer. The mixture was stirred in a vortex mixer for $30 \mathrm{~min}$ and then centrifuged at $12,000 \times \mathrm{g}$ for $2 \mathrm{~min}$. A volume of $10-12 \mu \mathrm{l}$ of the purified sequencing product was extracted and run on an $\mathrm{ABI}$ PRISM 3100 analyzer (Applied Biosystems).

\section{Characterization of Bacterial Genomes}

Full genome sequencing was performed using the HiScan ${ }^{\mathrm{TM}} \mathrm{SQ}$ system (Illumina, San Diego, CA, USA), generating 10,785,126 individual readings of $150 \mathrm{bp}$ in length. The genomes of $B$. amyloliquefaciens $\mathrm{Bs} 006$ and $P$. palleroniana PS006 were assembled using ARGO, a reference-guided assembler developed at NCBI, and SPAdes, a de novo assembler [43]. The draft genome was annotated using the Rapid Annotation using Subsystem Technology (RAST) server and the $\mathrm{nr}$ database, whilst antimicrobial resistance genes (ARGs) were identified using the SARG 2.0 database, RAST server, and $\mathrm{nr}$ database. Genome drafts were previously announced in Gamez et al. in 2015 and 2016 [37, 38]. The COGs (Clusters of Orthologous Groups of proteins) categories were identified using the eggNOG-mapper tool (http://eggnog-mapper.embl. de/) employing the default options [44].

To quantify the number of genes/factors occurring in the genomes of the two strains involved in functions that are relevant in plant-microbe interactions, the online tool PIFAR (Plant-bacteria Interaction Factors Resource) was used [45].

Secondary metabolites biosynthetic clusters were detected with the antiSMASH tool (https://antismash. secondarymetabolites.org), using the default setting, and "strict" detection strengthness [46].

\section{Results}

\section{FISH-CLSM Analysis of Colonized Roots}

Bacillus amyloliquefaciens Bs006 was very abundant (order of magnitude: $10^{10}$ cells $/ \mathrm{cm}^{3}$ plant root tissue) on the rhizoplane (epiphytically) and between root hairs, from $1 \mathrm{~h}$ after inoculation (AI) to $48 \mathrm{~h} \mathrm{AI}$ (Figs. 1a, d and 2). From $96 \mathrm{~h} \mathrm{AI}$ to $30 \mathrm{~d} \mathrm{AI}$, the density strongly decreased to an order of magnitude of $10^{7}$ cells $/ \mathrm{cm}^{3}$ plant root tissue (Figs. 1g, j, m and 2). Pseudomonas palleroniana Ps006 was detected mostly as single cells (often showing a dividing morphology) until $48 \mathrm{~h}$ AI (Figs. 1b, e and 2), markedly less abundant than B. amyloliquefaciens Bs006, and localized on the root hairs (order of magnitude: $10^{7}$ cells $/ \mathrm{cm}^{3}$ plant root tissue). At $96 \mathrm{~h} \mathrm{AI}$ and $15 \mathrm{~d} \mathrm{AI}$, the density progressively increased (Figs. $1 \mathrm{~h}, \mathrm{k}$ and 2 ), and it was maximal $30 \mathrm{~d} \mathrm{AI}$ (order of magnitude: $10^{9}$ cells $/ \mathrm{cm}^{3}$ plant root tissue)
(Figs. 1n and 2). B. amyloliquefaciens Bs006 remained limited to the epiphytic space, colonizing only the root and especially root hair surfaces (Fig. 3). On the other hand, P. palleroniana Ps006 clearly colonized banana roots endophytically, starting from $96 \mathrm{~h}$ AI. The preferential sites of endophytic colonization were the root hairs (Fig. 4; Fig. S2); however, interesting intracellular colonization of single plant cells within the main root was also observed (Fig. 5). The autofluorescence of those plant cells was evidently lower than the surrounding cells (Fig. 5a), suggesting that they were dead and then became occupied by strain Ps006 bacteria (Fig. 5b-e).

No signal was detected in the non-inoculated roots (Fig. 1c, f, $\mathrm{i}, 1, \mathrm{o}$ ) or in the inoculated roots hybridized with the negative FISH-probe NONEUB (Fig. S3).

The trends of the cell densities in the two strains (Fig. 2) were negatively correlated (Spearman's rho $=-0.74, p=$ 0.003 ), indicating complementarity of their colonization dynamics at a temporal scale.

\section{In Silico Analysis of the Genome for Plant Growth- Promoting Traits}

The genome assembly of B. amyloliquefaciens Bs006 has been deposited at GenBank with accession number LJAU00000000 [37]. Details of the genome analysis are reported in Tables S1 and S2. Annotation by RAST (Table S4) revealed 653 factors involved in plant growth-promoting activity and plant-microbe interactions (Table 1). Regarding P. palleroniana Ps006, only the factor category "dormancy and sporulation" was more highly represented, due to the ability of Bacillus to sporulate (Tables 1 and 2).

The genome assembly of $P$. palleroniana Ps006 was deposited in GenBank, with accession number LRMR00000000 [38]. Details of the genome analysis are reported in Tables S1 and S3. Annotation by RAST (Table S5) showed 1022 factors or genes involved in plant growth-promoting activity and plant-microbe interactions. All factor categories except dormancy and sporulation were more highly represented in this strain. In particular, the categories "virulence, disease, and defense," "pigments," and the category regarding the metabolism of elements generally showed the highest difference (>twofold) (Table 1). Concerning the category "virulence, disease, and defense," the breakdown of specific factors showed that this difference was due to the highest number of "resistance to antibiotics and toxic compounds" factors (Table 2). On the other hand, bacteriocins and ribosomally synthesized antimicrobial peptides were slightly higher in B. amyloliquefaciens Bs006 (Table 2).

Similar to the RAST results, PIFAR identification of genes responsible for functions involved in plant-microbe interactions (Tab. S6-S7) showed that the two rhizobacteria have clearly different functional profiles (Tables 1 and 2). Genes related to drug resistance, detoxification, biosynthesis of siderophores, pigments and vitamins, and metabolism of elements, as well as adhesion potential, were more abundant in $P$. palleroniana 
Fig. 1 Confocal microscopy series of FISH-stained samples showing the colonization dynamics of Bacillus amyloliquefaciens Bs006 and Pseudomonas palleroniana Ps006 on banana roots at different time points. Volume-rendered images were created with Imaris software. Images of non-inoculated roots without detectable bacterial signals are also shown. Scale bars: a, $\mathbf{d}, \mathbf{f}, \mathbf{i}, \mathbf{j}, \mathbf{k}, \mathbf{n}, \mathbf{o}=20 \mu \mathrm{m} ; \mathbf{b}, \mathbf{c}, \mathbf{e}, \mathbf{g}$ $\mathbf{h}, \mathbf{l}=30 \mu \mathrm{m} ; \mathbf{m}=10 \mu \mathrm{m}$
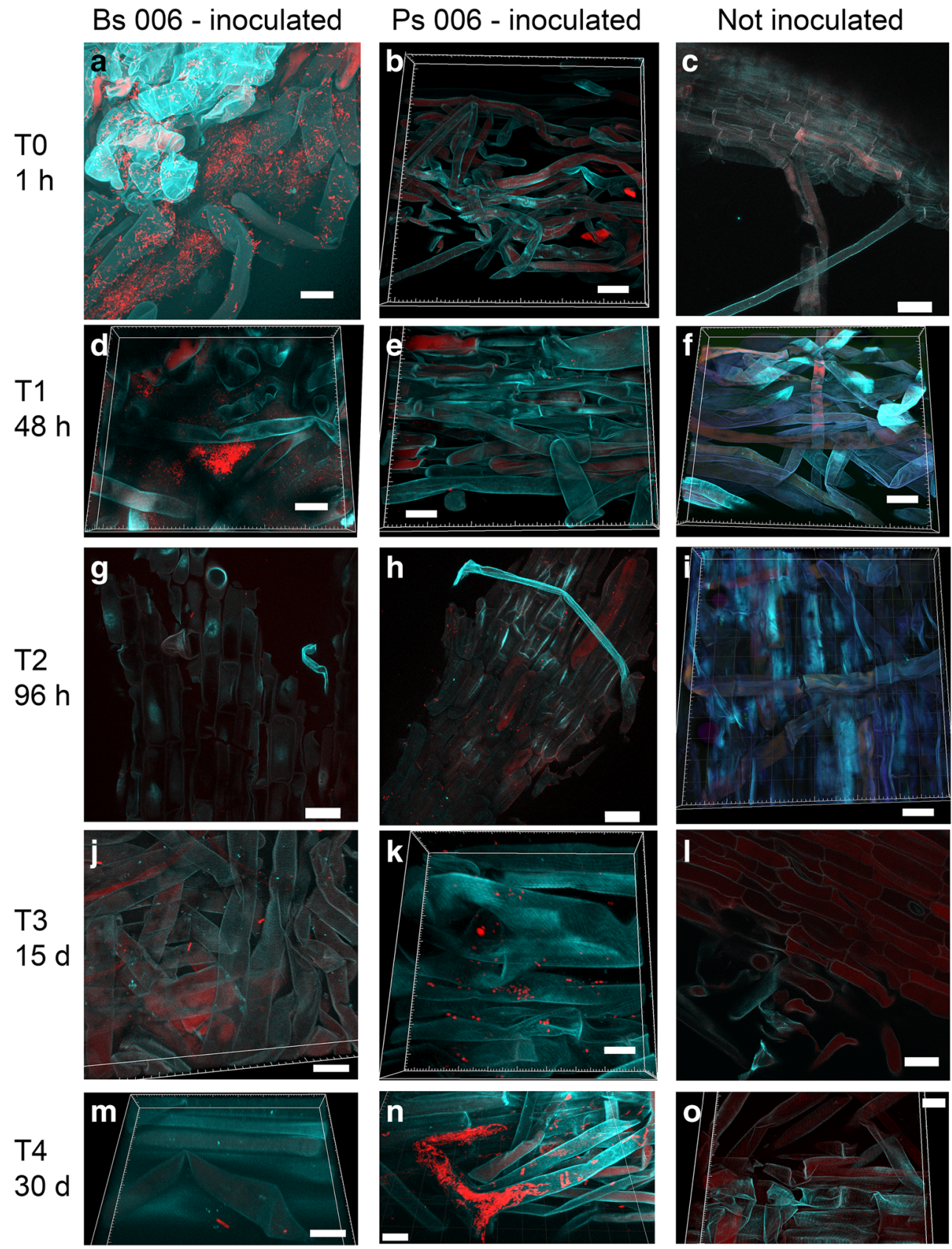

Ps006. Meanwhile, B. amyloliquefaciens Bs006 showed a notably higher number of genes involved in antibiotic synthesis, exopolysaccharides production, microbe-associated molecular patterns, and biofilm formation (Table 1). In total, consistent with the RAST analysis, a higher number of plant-microbe interaction factors were found in $P$. palleroniana Ps006 than in B. amyloliquefaciens Bs006, although the difference (167 vs. 160 , respectively) was notably less marked. Beyond the differences in abundance, the types of factors or genes detected were clearly different between the two strains (Table 2). Regarding the proportion of individual factors identified in the two bacterial strains, the only incongruity found between the RAST and PIFAR analysis was related to pigments (Tables 1 and 2).
The antiSMASH analysis output was congruent with both previous analysis tools. More biosynthetic clusters of secondary metabolites (basically antimicrobial factors) were identified for B. amyloliquefaciens than for P. palleroniana (Tables 1 and 2).

\section{Discussion}

This study was designed and built on two previous studies, where we found that the two PGPR strains B. amyloliquefaciens Bs006 and $P$. palleroniana Ps006, selected as best promoters of banana cv. Williams [32], induced changes in the host transcripts at different times after inoculation [33]. Therefore, we performed a 


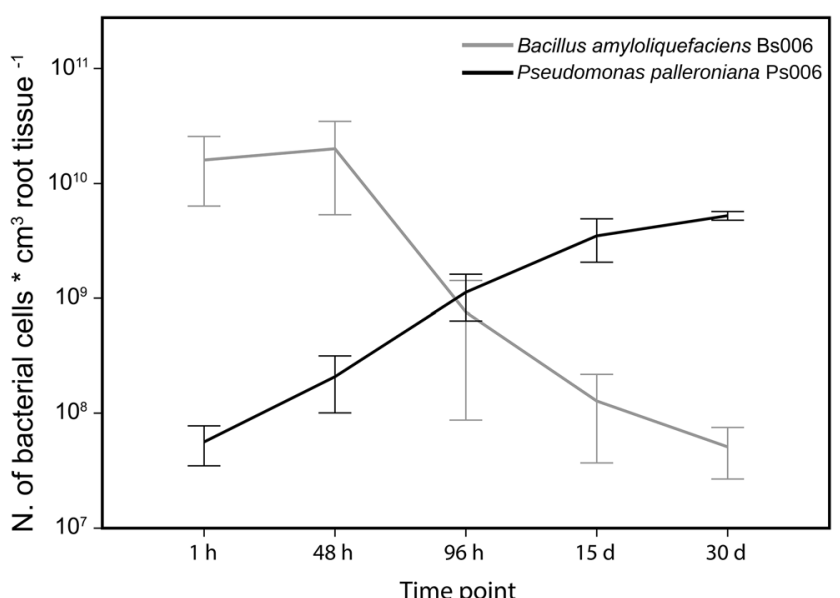

Fig. 2 Quantification of the bacterial cell density in the banana root obtained by quantitative analysis of the confocal series after conversion of the original FISH-conferred signals into spheres (bacteria) and isosurfaces (root tissue)

FISH-CLSM analysis of the same root samples used for transcriptomics and compared the genetic features that were possibly responsible for the differences found.

\section{Differential Colonization Patterns at Spatial and Temporal Scales}

Our investigation confirmed that the two rhizobacteria have different colonization dynamics in banana roots: Bs006 appears very abundant immediately after inoculation until $48 \mathrm{~h}$, and then sharply decreases. Ps006, on the other hand, is less abundant until $48 \mathrm{~h}$, whereupon it increases dramatically. This confirmed our first hypothesis about a temporal scale separation of the two PGPR on banana roots. Moreover, the colonization behavior is also very different: Bs006 colonizes the root epiphytically, while Ps006 becomes clearly endophytic. This confirmed our second hypothesis about the spatial scale separation of the two PGPR on banana roots.

Efficient colonization of plant roots by PGPR is essential to achieving a long-term, beneficial association, for three reasons: (i) if the rhizobacteria do not bind to the root of the plant, the substances that they excrete will spread in the rhizosphere and will be consumed by other soil microorganisms before reaching the plant; (ii) without a firm bond, water can eliminate bacteria from the rhizoplane; and (iii) the root areas that are not associated with PGPR are more vulnerable to phytopathogen colonization [2]. According to our results, P. palleroniana Ps006 is more suitable for long-term colonization of banana roots. However, the relatively short occurrence of B. amyloliquefaciens Bs006 also clearly affects the banana plants $[32,33]$. The observation made at $\mathrm{T} 0$ in the current study confirmed our previous observations [32].

Bacillus amyloliquefaciens in banana plants stimulated the formation of organic compounds such as fumaric acid that participated significantly in biofilm formation, growth promotion activity, and gene expression [47]. In contrast, $P$. palleroniana Ps006 is endophytic. Consistent with our observations, previous works also detected P. palleroniana in the endosphere of banana plants $[48,49]$. It seems to be a well-adapted species to the banana endosphere habitat. Additionally, we observed an interesting colonization pattern: the first signs of endophytic colonization by strain Ps006 were the invasion of apparently dead plant cells (Fig. 5). This was observed already at T2, $96 \mathrm{~h}$ after inoculation. This might be the invasion strategy used by P. palleroniana Ps006 to enter the root endosphere, followed by later colonization of other internal tissues (root hairs). In fact, previous works have shown that root hairs can be colonized endophytically by Gammaproteobacteria that move internally from the main root into the emerging root hairs [50]. The
Fig. 3 FISH-CLSM images showing the epiphytic colonization of banana root hairs by Pseudomonas palleroniana Ps006 $1 \mathrm{~h}$ after inoculum. a Root tissue autofluorescence (cyan); b signal of the Cy3-labeled EUB338MIX universal probe for bacteria (red); c overlay of $\mathbf{a}-\mathbf{b}$; d three-dimensional model of $\mathbf{c}$, showing bacteria as spheres and root tissue as isosurfaces; $\mathbf{e}$ flipped view of $\mathbf{d}$ showing no bacterial cells inside the root hairs. Scale bars: a-d $30 \mu \mathrm{m}$; $20 \mu \mathrm{m}$

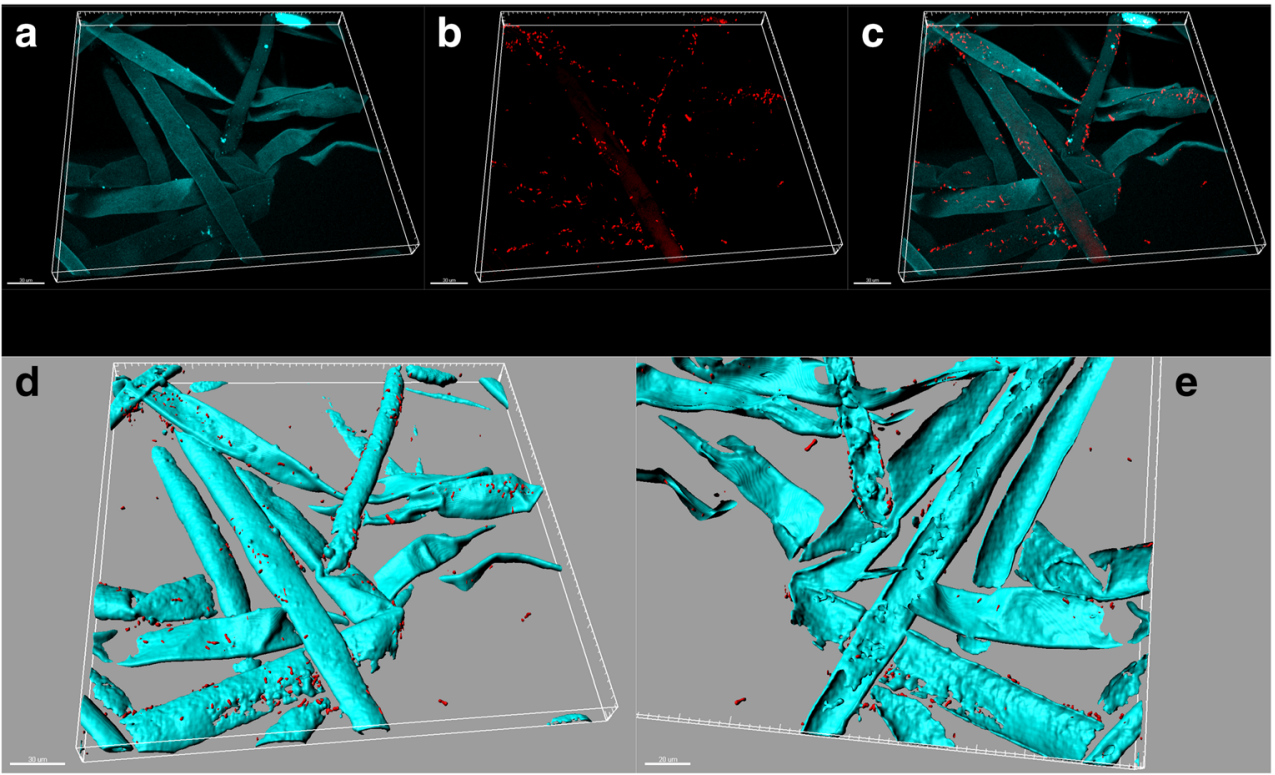


Fig. 4 FISH-CLSM images showing the endophytic colonization of banana root hairs by Pseudomonas palleroniana Ps006 30 days after inoculum. a Root tissue autofluorescence (cyan); $\mathbf{b}$ signal of the Cy3labeled EUB338MIX universal probe for bacteria (red); c overlay of $\mathbf{a}-\mathbf{b} ; \mathbf{d}$ three-dimensional model of $\mathbf{c}$ showing bacteria as spheres and root tissue as isosurfaces. Scale bars: $10 \mu \mathrm{m}$

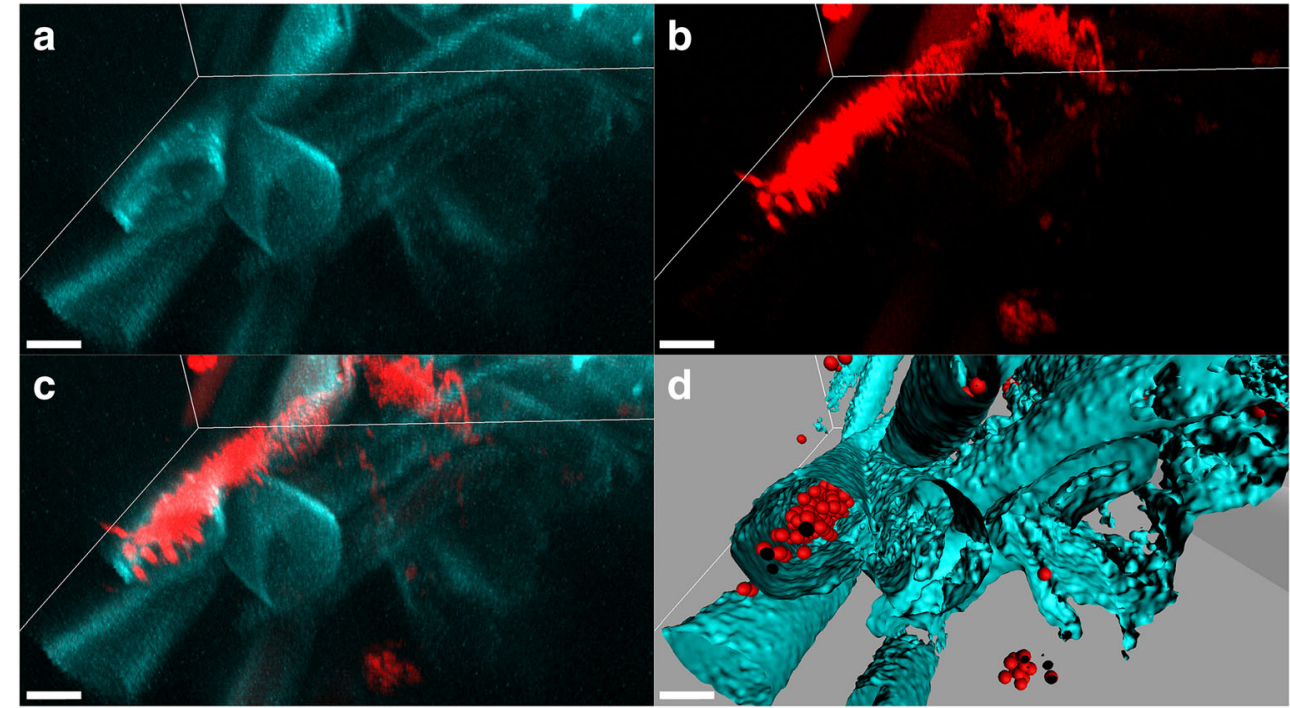

endophytic behavior of $P$. palleroniana, together with its beneficial properties demonstrated in our previous works $[32,33]$ and in other works on banana [48, 49] and other crops [51, 52], make it an optimal candidate as an efficient and environmentally friendly biofertilizer.

\section{Differences in the Genetic Background Explain Different Colonization Patterns}

Despite a generally similar pattern of functional and structural genes in the two genomes (Fig. 6), P. palleroniana possesses a higher number of genes/factors involved in plant-microbe interactions compared to B. amyloliquefaciens. Moreover, there are notable differences between the two strains regarding the specific genes involved in the potential beneficial effects on the banana host plant. In P. palleroniana Ps006, more genes involved in potassium, nitrogen, iron, sulfur, and phosphorus metabolism were found, whereas in B. amyloliquefaciens BS006, only sporulation factors were notably more abundant (Tables 1 and 2). As for plant stress and defense, PGPR can aid in active plant growth in conditions of abiotic or biotic stresses [53]. PGPR produce repressive substances that increase the natural resistance to phytopathogens and pests [9], such as hydrolytic enzymes (chitinases, cellulases, and proteases), as well as various antibiotics, volatile organic compounds (VOCs), exopolysaccharides (EPS), and siderophores that protect plants against
Fig. 5 FISH-CLSM images showing the endophytic colonization of banana roots by Pseudomonas palleroniana Ps006 $96 \mathrm{~h}$ after inoculum. a Root tissue autofluorescence (cyan); $\mathbf{b}$ signal of the Cy3-labeled

EUB338MIX universal probe for bacteria (red); $\mathbf{c}$ overlay of $\mathbf{a}-\mathbf{b} ; \mathbf{d}$ volume rendering of $\mathbf{c}$; $\mathbf{e}$ threedimensional model of $\mathbf{d}$, showing bacteria as spheres and root tissue as isosurfaces. Scale bars: $10 \mu \mathrm{m}$
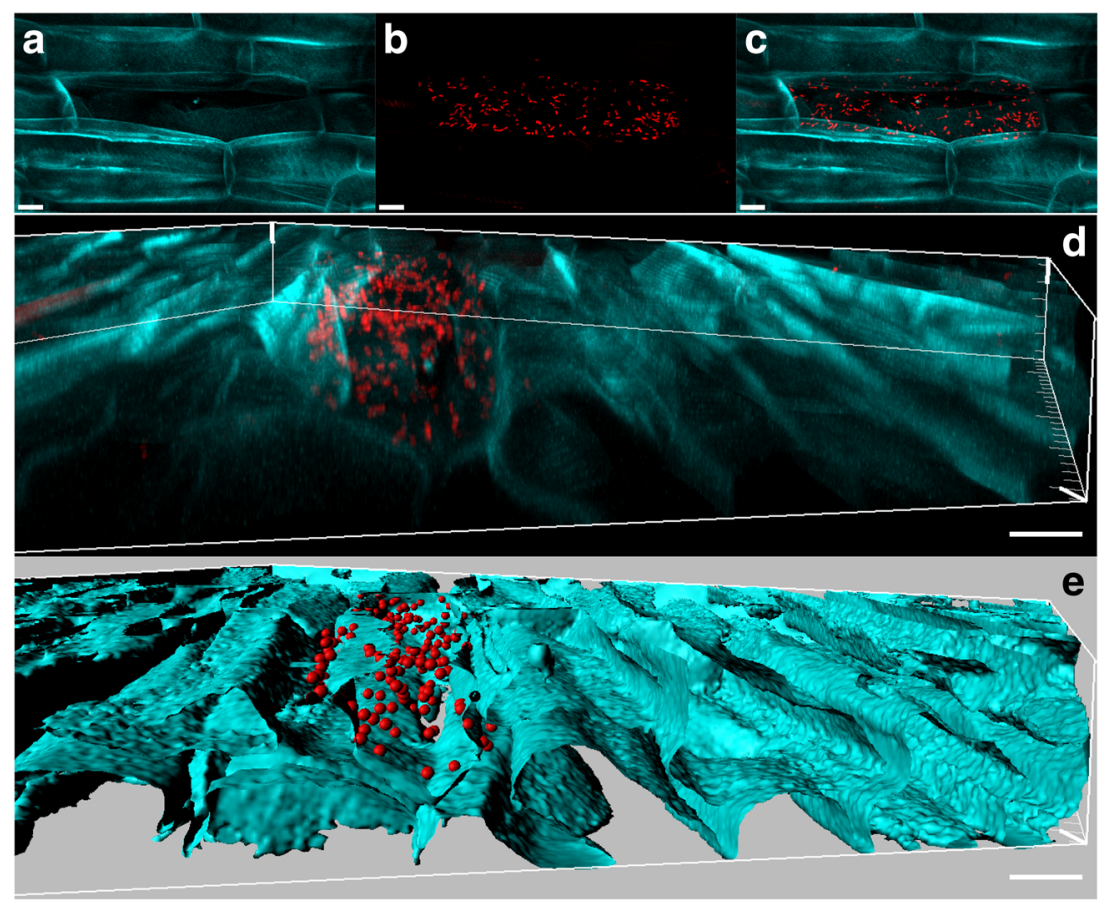
Table 1 Number of genes involved in plant growth-promoting activity and plant-microbe interactions in Bacillus amyloliquefaciens Bs006 and Pseudomonas palleroniana Ps006, as detected by in silico genome analysis (RAST, PIFAR, and antiSMASH tools)

\begin{tabular}{|c|c|c|c|}
\hline \multirow[t]{2}{*}{ Analysis tool } & \multirow[t]{2}{*}{ Factor type } & \multicolumn{2}{|c|}{ Number of factors/genes detected $*$} \\
\hline & & $\begin{array}{l}\text { Bacillus } \\
\text { amyloliquefaciens Bs006 }\end{array}$ & $\begin{array}{l}\text { Pseudomonas } \\
\text { palleroniana } \text { Ps006 }\end{array}$ \\
\hline \multirow[t]{10}{*}{ RAST 2.0} & Dormancy and sporulation & 116 & 3 \\
\hline & Cofactors, vitamins, prosthetic groups & 200 & 279 \\
\hline & Environmental stress response & 108 & 181 \\
\hline & Virulence, disease, and defense & 67 & 149 \\
\hline & Sulfur metabolism & 39 & 94 \\
\hline & Iron acquisition and metabolism & 32 & 92 \\
\hline & Phosphorus metabolism & 31 & 78 \\
\hline & Pigments & 20 & 69 \\
\hline & Nitrogen metabolism & 31 & 52 \\
\hline & Potassium metabolism & 9 & 25 \\
\hline \multirow[t]{17}{*}{ PIFAR } & Antibiotics & 65 & 22 \\
\hline & EPS & 18 & 15 \\
\hline & MAMP & 16 & 4 \\
\hline & Biofilm & 6 & 1 \\
\hline & Volatiles & 4 & 2 \\
\hline & Hormone & 3 & 2 \\
\hline & PCWDE & 4 & 1 \\
\hline & Pigment & 4 & 0 \\
\hline & Toxin & 3 & 0 \\
\hline & MDRs & 14 & 44 \\
\hline & Detoxification & 4 & 25 \\
\hline & Siderophore & 6 & 18 \\
\hline & Adhesion & 1 & 17 \\
\hline & Metabolism & 10 & 12 \\
\hline & Protease & 1 & 2 \\
\hline & Type III effector & 0 & 1 \\
\hline & LPS & 1 & 1 \\
\hline antiSMASH & Secondary metabolite biosynthetic cluster & 13 & 9 \\
\hline
\end{tabular}

*Numbers in bold indicate the strain with higher abundance. RAST data obtained from [37, 38]. MDR microbial drug resistance, EPS exopolysaccharides, MAMP microbe-associated molecular pattern, $P C W D E$ plant cell wall-degrading enzymes

phytopathogens $[9,54]$. The $P$. palleroniana Ps006 strain used in the current study has a genome that contains more genes for resistance to antibiotics and toxic compounds (Tables 1 and 2). Further, the in silico genome analysis and the online tool PIFAR were used to detect the presence of genes involved in plantmicrobe interactions; the results were mostly coherent with those of RAST (except for pigments). Similar to the RAST analysis, PIFAR also highlighted notable differences between the two strains (Tables 1 and 2). Considering the antiSMASH analysis, we confirm that the three analysis tools generated coherent outputs among one another, with very few incongruities.

All these distinctive genetic traits explain the different colonization behaviors observed between P. palleroniana Ps006 and B. amyloliquefaciens Bs006 on banana roots and substantiate the various effects on plant growth and gene expression found in our previous works $[33,34]$. In particular, the endophytic behavior of $P$. palleroniana Ps006 seems to be associated with a higher number of genes involved in drug resistance, detoxification, adhesion, siderophore/pigment/vitamin synthesis and, in general, nutrient metabolism; on the other hand, antibiotic synthesis, exopolysaccharides production, microbe-associated molecular patterns, and biofilm formation potential seem to be more related to $B$. amyloliquefaciens and banana root surface (although this association was only short-term in our study).

\section{Conclusions}

Studies like this are necessary to understand the ecology and the interactions of PGPR with the inoculated plants at spatial and 


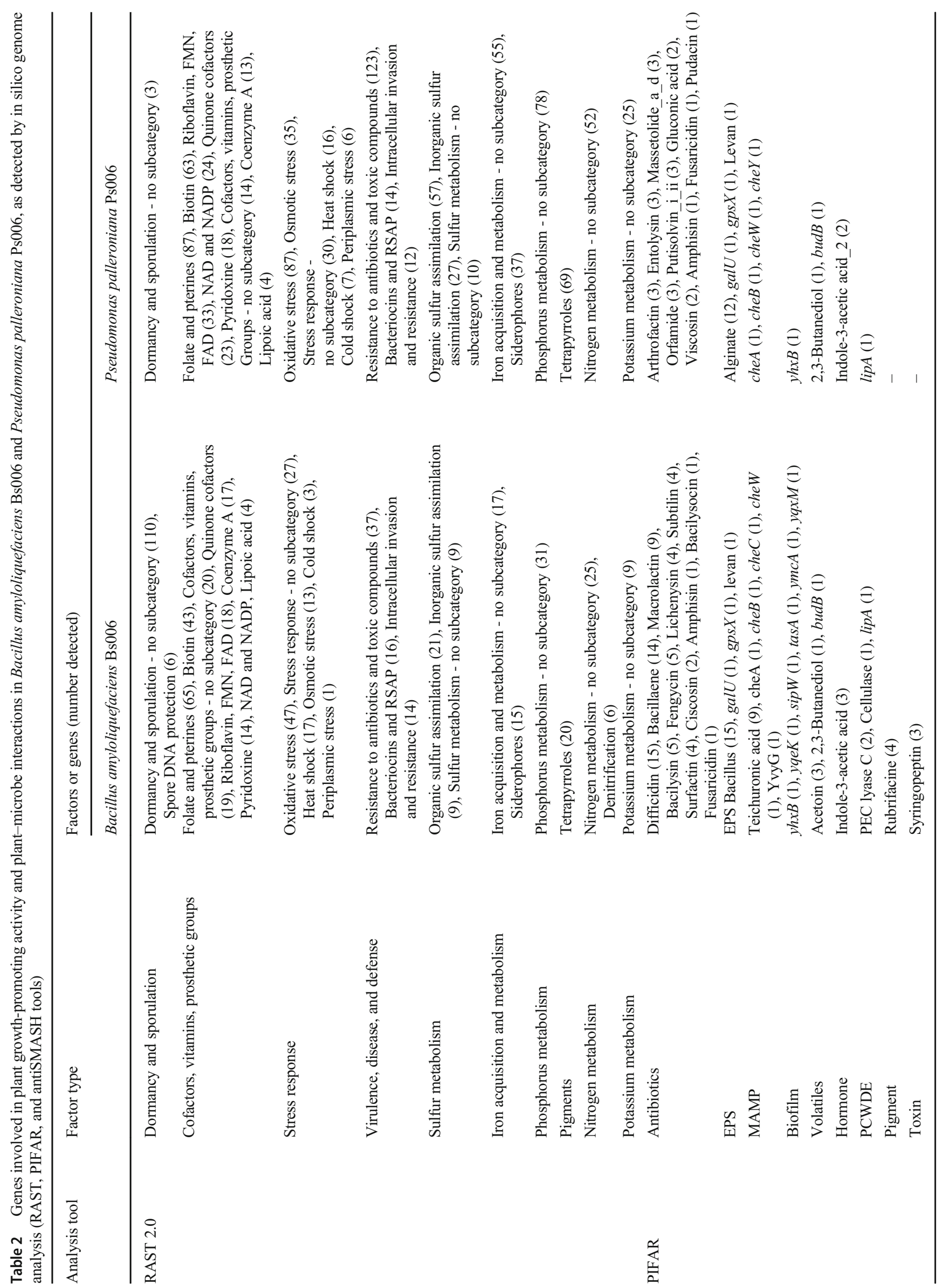




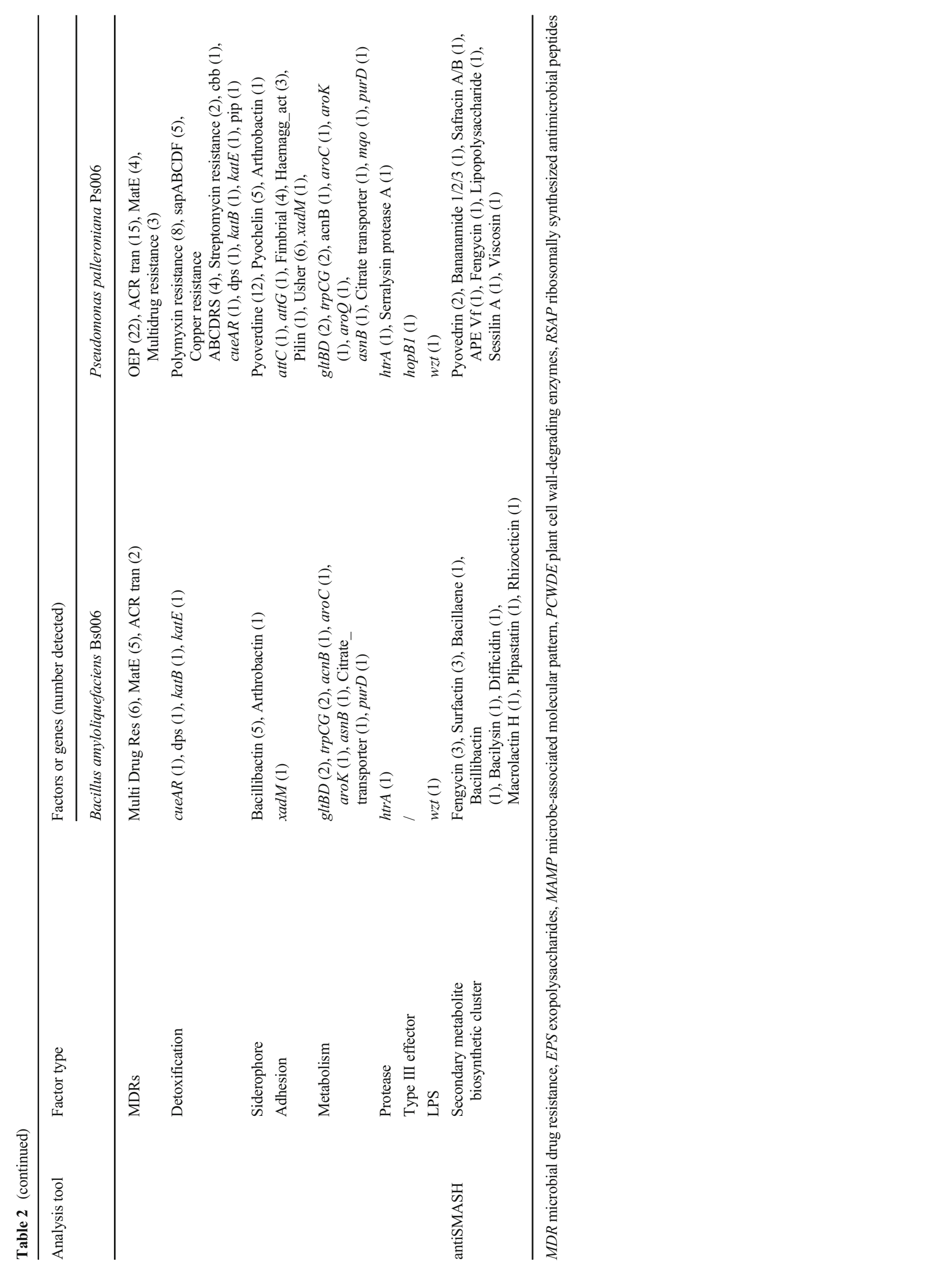


Fig. 6 Genes categorized in subsystems or general functions in a Bacillus amyloliquefaciens Bs006 and b Pseudomonas palleroniana Ps006, according to the annotation system in RAST 2.0
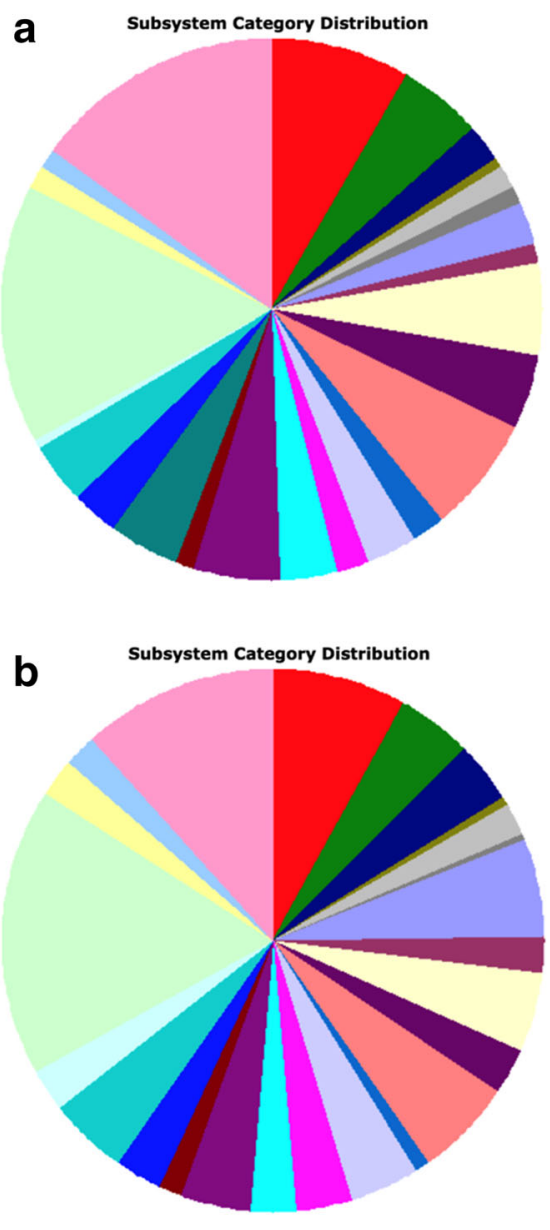

Subsystem Feature Counts

Cofactors, Vitamins, Prosthetic Groups, Pigments (242) $\boxplus$ Cell Wall and Capsule (137)

Virulence, Disease and Defense (68)

Potassium metabolism (9)

Photosynthesis (0)

Miscellaneous (46)

Phages, Prophages, Transposable elements, Plasmids (31) (1) Membrane Transport (69)

- Iron acquisition and metabolism (32)

RNA Metabolism (158)

Nucleosides and Nucleotides (126)

Protein Metabolism (194)

- Cell Division and Cell Cycle (54)

Motility and Chemotaxis (84)

Regulation and Cell signaling (58)

Secondary Metabolism (6)

Fatty Acids, Lipids, and

Fatty Acids, Lipids, and Isoprenoids (156)

Nitrogen Metabolism (31)

Dormancy and Sporulation (116)

Stress Response (108)

Metabolism of Aromatic Compounds (12)

Amino Acids and Derivatives (440)

Sulfur Metabolism (39)

Phosphorus Metabolism (31)

Carbohydrates (415)

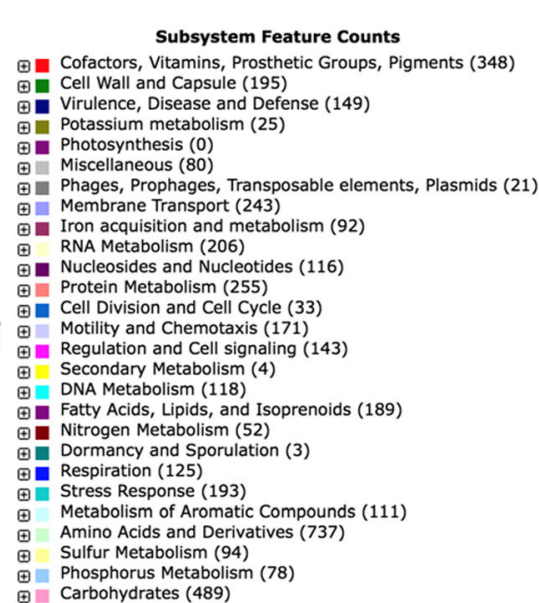

temporal scales. The obtained information can then be used to optimize the protocol of biofertilizer formulation and application to maximize its efficacy. In this work, we showed a complementarity colonization dynamic between B. amyloliquefaciens Bs006 and P. palleroniana Ps006 (earlier vs. later), as well as complementarity in habitat preference (epiphytic vs. endophytic). The different genetic background related to functions involved in plant-microbe interactions supports and substantiates the different colonization dynamics observed. Our results suggest that the two strains could theoretically be inoculated on the plant simultaneously, without competing for the niche. This means that they might be used together in a single biofertilizer formulation. Moreover, this appealing hypothesis needs to be tested in the future with co-inoculation experiments, which might also reveal further beneficial effects on banana growth by synergistic microbe-microbe interactions.

Acknowledgements We thank Dr. Stefanie Reissmann (Marburg, Germany) for allowing M.C. to use the confocal microscope at the Max Plank Institute for terrestrial microbiology (MPI Marburg).

Code Availability Not applicable.

Funding Information Open access funding provided by Università del Salento within the CRUI-CARE Agreement. We acknowledge the
Corporación Colombiana de Investigación Agropecuaria (AGROSAVIA) for financing this research with public resources from the Ministerio de Agricultura y Desarrollo Rural [Ministry of Agriculture and Rural Development] (MADR).

Availability of Data and Material The genome sequences of Bacillus amyloliquefaciens Bs006 and Pseudomonas palleroniana Ps006 analyzed during the current study are available in the GenBank repository [www.ncbi.nlm.nih.gov/nuccore/LJAU00000000; www.ncbi.nlm.nih. gov/nuccore/LRMR00000000].

\section{Compliance with Ethical Standards}

Conflicts of Interest/Competing Interests The authors declare that there are no conflicts of interest/competing interests in this study.

Ethics Approval Not applicable.

Consent to Participate Not applicable.

Consent for publication Not applicable.

Open Access This article is licensed under a Creative Commons Attribution 4.0 International License, which permits use, sharing, adaptation, distribution and reproduction in any medium or format, as long as you give appropriate credit to the original author(s) and the source, provide a link to the Creative Commons licence, and indicate if 
changes were made. The images or other third party material in this article are included in the article's Creative Commons licence, unless indicated otherwise in a credit line to the material. If material is not included in the article's Creative Commons licence and your intended use is not permitted by statutory regulation or exceeds the permitted use, you will need to obtain permission directly from the copyright holder. To view a copy of this licence, visit http://creativecommons.org/licenses/by/4.0/.

\section{References}

1. FAO - Food and Agriculture Organization of the United States (2018) Banana Statistical Compendium 2017. http://www.fao.org/ economic/est/est-commodities/bananas/bananafacts/it/\#. XnD7RnJ71PY Accessed 17 March 2020

2. Mia MB, Shamsuddin Z, Mahmood M (2010) Use of plant growth promoting bacteria in banana: a new insight for sustainable banana production. Int J Agric Biol 12:459-467

3. Akhtar A, Hisamuddin M, Robab A, Sharf R (2012) Plant growth promoting Rhizobacteria: an overview. J Nat Prod Plant Res 2:1931

4. Raupach GS, Kloepper JW (1998) Mixtures of plant growthpromoting rhizobacteria enhance biological control of multiple cucumber pathogens. Phytopathology 88:1158-1164

5. Kloepper J, Rodriguez-Kabana R, Zehnder A, Murphy J, Sikora E, Fernandez C (1999) Plant root-bacterial interactions in biological control of soilborne diseases and potential extension to systemic and foliar diseases. Australas Plant Pathol 28:21-26

6. Esitken A, Yildiz HE, Ercisli S, Donmez MF, Turan M, Gunes A (2010) Effects of plant growth promoting bacteria (PGPB) on yield, growth and nutrient contents of organically grown strawberry. Sci Hortic 124:62-66

7. Rowe HC, Walley JW, Corwin J, Chan EK-F, Dehesh K, Kliebenstein DJ (2010) Deficiencies in jasmonate-mediated plant defense reveal quantitative variation in Botrytis cinerea pathogenesis. PLoS Pathol 6:e1000861

8. Ahemad M, Kibret M (2014) Mechanisms and applications of plant growth promoting rhizobacteria: current perspective. J King Saud Univ Sci 26:1-20

9. Gupta G, Parihar SS, Ahirwar NK, Snehi SK, Singh V (2015) Plant growth promoting rhizobacteria (PGPR): current and future prospects for development of sustainable agriculture. J Microbiol Biochem Technol 7:096-102

10. Cardinale M, Ratering S, Suarez C, Montoya AMZ, Geissler-Plaum R, Schnell S (2015) Paradox of plant growth promotion potential of rhizobacteria and their actual promotion effect on growth of barley (Hordeum vulgare L.) under salt stress. Microbiol Res 181:22-32

11. Adesemoye AO, Obini M, Ugoji EO (2008) Comparison of plant growth-promotion with Pseudomonas aeruginosa and Bacillus subtilis in three vegetables. Braz J Microbiol 39:423-426

12. Dias A, Santos SG, Vasconcelos VDS, Radl V, Xavier GR, Rumjanek NG, Ribeiro RL (2013) Screening of plant growth promoting rhizobacteria for the development of vegetable crops inoculants. Afr J Microbiol Res 7:2087-2092

13. Zaidi A, Ahmad E, Khan MS, Saif S, Rizvi A (2015) Role of plant growth promoting rhizobacteria in sustainable production of vegetables: current perspective. Sci Hortic 193:231-239

14. Esitken A, Karlidag H, Ercisli S, Turan M, Sahin F (2003) The effect of spraying a growth promoting bacterium on the yield, growth and nutrient element composition of leaves of apricot (Prunus armeniaca L. cv. Hacihaliloglu). Aust J Agric Res 54: 377-380
15. Esitken A, Pirlak L, Turan M, Sahin F (2006) Effects of floral and foliar application of plant growth promoting rhizobacteria (PGPR) on yield, growth and nutrition of sweet cherry. Sci Hortic 110:324 327

16. Orhan E, Esitken A, Ercisli S, Turan M, Sahin F (2006) Effects of plant growth promoting rhizobacteria (PGPR) on yield, growth and nutrient contents in organically growing raspberry. Sci Hortic 111: $38-43$

17. Aslantas R, Cakmakci R, Sahin F (2007) Effect of plant growth promoting rhizobacteria on young apple tree growth and fruit yield under orchard conditions. Sci Hortic 111:371-377

18. Karlidag H, Esitken A, Turan M, Sahin F (2007) Effects of root inoculation of plant growth promoting rhizobacteria (PGPR) on yield, growth and nutrient element contents of leaves of apple. Sci Hortic 114:16-20

19. Rivera-Cruz MC, Trujillo-Narcía A, Cordova-Ballona G, Kohler J, Caravaca F, Roldan A (2008) Poultry manure and banana waste are effective biofertilizer carriers for promoting plant growth and soil sustainability in banana crops. Soil Biol Biochem 40:3092-3095

20. Lugtenberg B, Kamilova F (2009) Plant-growth-promoting rhizobacteria. Annu Rev Microbiol 63:541-556

21. Olanrewaju OS, Glick BR, Babalola OO (2017) Mechanisms of action of plant growth promoting bacteria. World J Microbiol Biotechnol 33:197

22. Spaepen S, Vanderleyden J (2011) Auxin and plant-microbe interactions. Cold Spring Harb Perspect Biol 3(4):a001438

23. Glick BR (2012) Plant growth-promoting bacteria: mechanisms and applications. Scientifica 2012:963401. https://doi.org/10. $6064 / 2012 / 963401$

24. Shilev S (2013) Soil rhizobacteria regulating the uptake of nutrients and undesirable elements by plants. In: Arora N (ed) Plant microbe symbiosis: fundamentals and advances. Springer, New Delhi, pp 147-167

25. Kang BG, Kim WT, Yun HS, Chang SC (2010) Use of plant growth-promoting rhizobacteria to control stress responses of plant roots. Plant Biotechnol Rep 4:179-183

26. Ozturk A, Caglar O, Sahin F (2003) Yield response of wheat and barley to inoculation of plant growth promoting rhizobacteria at various levels of nitrogen fertilization. J Plant Nutr Soil Sci 166: 262-266

27. Bhattacharyya PN, Jha DK (2012) Plant growth-promoting rhizobacteria (PGPR): emergence in agriculture. World $\mathrm{J}$ Microbiol Biotechnol 28:1327-1350

28. Cornelis $P$ (2010) Iron uptake and metabolism in pseudomonads. Appl Microbiol Biotechnol 86:1637-1645

29. Lanteigne C, Gadkar VJ, Wallon T, Novinscak A, Filion M (2012) Production of DAPG and HCN by Pseudomonas sp. LBUM300 contributes to the biological control of bacterial canker of tomato. Phytopathology 102:967-973

30. Arora NK, Tewari S, Singh R (2013) Multifaceted plant-associated microbes and their mechanisms diminish the concept of direct and indirect PGPRs. In: Arora N (ed) Plant microbe symbiosis: fundamentals and advances. Springer, New Delhi, pp 411-449

31. Mousa WK, Shearer C, Limay-Rios V, Ettinger CL, Eisen JA, Raizada MN (2016) Root-hair endophyte stacking in finger millet creates a physicochemical barrier to trap the fungal pathogen Fusarium graminearum. Nat Microbiol 1:16167. https://doi.org/ 10.1038/nmicrobiol.2016.167

32. Gamez R, Cardinale M, Montes M, Ramirez S, Schnell S, Rodriguez F (2019a) Screening, plant growth promotion and root colonization pattern of two rhizobacteria (Pseudomonas fluorescens Ps006 and Bacillus amyloliquefaciens Bs006) on banana cv. Williams (Musa acuminata Colla). Microbiol Res 220:1220

33. Gamez R, Rodriguez F, Vidal NM, Ramirez S, Alvarez RV, Landsman D, Mariño-Ramirez L (2019b) Banana (Musa 
acuminata) transcriptome profiling in response to rhizobacteria: Bacillus amyloliquefaciens Bs006 and Pseudomonas fluorescens Ps006. BMC Genomics 20:378. https://doi.org/10.1186/s12864019-5763-5

34. Moter A, Göbel UB (2000) Fluorescence in situ hybridization (FISH) for direct visualization of microorganisms. J Microbiol Methods 41:85-112

35. Cardinale M (2014) Scanning a microhabitat: plant-microbe interactions revealed by confocal laser microscopy. Front Microbiol 5: 94

36. Murashige T, Skoog F (1962) A revised medium for rapid growth and bio assays with tobacco tissue cultures. Physiol Plant 15:473497

37. Gamez RM, Rodríguez F, Bernal JF, Agarwala R, Landsman D, Mariño-Ramírez L (2015) Genome sequence of the banana plant growth-promoting rhizobacterium Bacillus amyloliquefaciens BS006. Genome Announc 3:e1391-e01315

38. Gamez RM, Rodríguez F, Ramírez S, Gómez Y, Agarwala R, Landsman D, Mariño-Ramírez L (2016) Genome sequence of the banana plant growth-promoting rhizobacterium Pseudomonas fluorescens PS006. Genome Announc 4:e00329-e00316

39. Fan B, Blom J, Klenk HP, Borriss R (2017) Bacillus amyloliquefaciens, Bacillus velezensis, and Bacillus siamensis form an "operational group B. amyloliquefaciens" within the B. subtilis species complex. Front Microbiol 8:22

40. Cardinale M, Vieira de Castro Jr J, Müller H, Berg G, Grube M (2008) In situ analysis of the bacterial community associated with the reindeer lichen Cladonia arbuscula reveals predominance of Alphaproteobacteria. FEMS Microbiol Ecol 66:63-71

41. Amann RI, Binder BJ, Olson RJ, Chisholm SW, Devereux R, Stahl DA (1990) Combination of 16S rRNA-targeted oligonucleotide probes with flow cytometry for analyzing mixed microbial populations. Appl Environ Microbiol 56:1919-1925

42. Wallner G, Amann R, Beisker W (1993) Optimizing fluorescent in situ hybridization with rRNA-targeted oligonucleotide probes for flow cytometric identification of microorganisms. Cytometry 14: 136-143

43. Bankevich A, Nurk S, Antipov D, Gurevich AA, Dvorkin M, Kulikov AS, Lesin VM, Nikolenko SI, Pham S, Prjibelski AD (2012) SPAdes: a new genome assembly algorithm and its applications to singlecell sequencing. J Comput Biol 19:455-477

44. Huerta-Cepas J, Forslund K, Coelho LP, Szklarczyk D, Jensen LJ, Von Mering C, Bork P (2017) Fast genome-wide functional annotation through orthology assignment by eggNOG-mapper. Mol Biol Evol 34:2115-2122

45. Martínez-García PM, López-Solanilla E, Ramos C, RodríguezPalenzuela P (2016) Prediction of bacterial associations with plants using a supervised machine-learning approach. Environ Microbiol 18:4847-4861

46. Medema MH, Blin K, Cimermancic P, de Jager V, Zakrzewski P, Fischbach MA, Weber T, Takano E, Breitling R (2011) antiSMASH: rapid identification, annotation and analysis of secondary metabolite biosynthesis gene clusters in bacterial and fungal genome sequences. Nucleic Acids Res 39:W339-W346

47. Yuan J, Zhang N, Huang Q, Raza W, Li R, Vivanco JM, Shen Q (2015) Organic acids from root exudates of banana help root colonization of PGPR strain Bacillus amyloliquefaciens NJN-6. Sci Rep $5: 13438$

48. Ngamau CN, Matiru VN, Tani A, Muthuri CW (2012) Isolation and identification of endophytic bacteria of bananas (Musa spp.) in Kenya and their potential as biofertilizers for sustainable banana production. Afr J Microbiol Res 6:6414-6422

49. Nicomrat D, Soongsombat P, Suenonmueng N, Marjang N (2018) An antagonism of isolates of root-associated bacteria consortia habituating in banana rhizosphere. Appl Mech Mater 879:83-88

50. Cardinale M, Berg G (2014) Visualization of plant-microbe interactions. In: Lugtenberg B (ed) Principles of plant-microbe interactions. Springer International Publishing, Berlin, pp 299-306

51. Velivelli SL, Kromann P, Lojan P, Rojas M, Franco J, Suarez JP, Prestwich BD (2015) Identification of mVOCs from Andean rhizobacteria and field evaluation of bacterial and mycorrhizal inoculants on growth of potato in its center of origin. Microb Ecol 69: 652-667

52. Chandra D, Srivastava R, Glick BR, Sharma AK (2020) Rhizobacteria producing ACC deaminase mitigate water-stress response in finger millet (Eleusine coracana (L.) Gaertn.). 3 Biotech 10:65

53. Akhgar A, Arzanlou M, Bakker P, Hamidpour M (2014) Characterization of 1-aminocyclopropane-1-carboxylate (ACC) deaminase-containing Pseudomonas spp. in the rhizosphere of salt-stressed canola. Pedosphere 24:461-468

54. Nivya R (2015) A study on plant growth promoting activity of the endophytic bacteria isolated from the root nodules of Mimosa Pudica plant. Int J Innov Res Sci Eng Technol 4:6959-6968 